\title{
Navegar en la locura: el límite como posibilidad y sentido en El Camino de Santiago de Patricia Laurent Kullick
}

María Martínez Díaz

Martínez Díaz, M. (2022). Navegar en la locura: el límite como posibilidad y sentido en El Camino de Santiago de Patricia Laurent Kullick. Revista de Filología y Lingüística de la Universidad de Costa Rica, 48(1), e48437. doi: https://doi.org/10.15517/rfl.v48i1.48437

\section{(c) $\mathbb{P Q \Theta O}$}

Doi: https://doi.org/10.15517/rfl.v48i1.48437

URL: https://revistas.ucr.ac.cr/index.php/filyling/index 
Revista de Filología y Lingüística de la Universidad de Costa Rica

ISSN: 0377-628X

ISSN: 2215-2628

filyling@gmail.com

Universidad de Costa Rica

Costa Rica

\section{Navegar en la locura: el límite como posibilidad y sentido en El Camino de Santiago de Patricia Laurent Kullick}

Martínez Díaz, María

Navegar en la locura: el límite como posibilidad y sentido en El Camino de Santiago de Patricia Laurent Kullick Revista de Filología y Lingüística de la Universidad de Costa Rica, vol. 48, núm. 1, e48437, 2022

Universidad de Costa Rica, Costa Rica

Disponible en: https://www.redalyc.org/articulo.oa?id=33268016013

DOl: https://doi.org/10.15517/rfl.v48i1.48437

\section{(c) $\underset{\mathrm{BY}}{(\Theta \mathrm{NO}} \mathrm{No}$}

Esta obra está bajo una Licencia Creative Commons Atribución-NoComercial-SinDerivar 3.0 Internacional. 


\title{
Navegar en la locura: el límite como posibilidad y sentido en El Camino de Santiago de Patricia Laurent Kullick
}

\author{
Navigating Madness: The Limit as Possibility and Meaning in El Camino de Santiago by Patricia Laurent Kullick \\ Maria Martínez Díaz \\ Universidad de Costa Rica, San José, Costa Rica \\ maria.martinezdiaz@ucr.ac.cr \\ DOI: https://doi.org/10.15517/rfl.v48i1.48437 \\ Redalyc: https://www.redalyc.org/articulo.oa? \\ $\mathrm{id}=33268016013$
}

iD https://orcid.org/0000-0003-4454-4002

Recepción: 08 Febrero 2021

Aprobación: 15 Marzo 2021

\section{Resumen:}

Este artículo elabora una lectura de la novela de Patricia Laurent Kullick, El Camino de Santiago (2003), a partir del tema del viaje que se problematiza en el texto. El análisis se hace desde la propuesta de Michel Foucault (1972) en torno a la figura de la Nave de los locos, emblemática de cierta locura que viaja y suscita imaginarios en torno a sus manifestaciones. Posteriormente, esta imagen de la nave de los locos se va a enriquecer con la propuesta de Deleuze (2015), y su noción del pliegue, que el autor relaciona con la nave de los locos analizada en Historia de la Locura. Con base en la noción del pliegue y del tema del viaje, la supuesta esquizofrenia de la protagonista toma una forma metafórica que permite explorar un sentido de la locura que evoca el escape, la huida, pero ante todo, un viaje al interior y el exterior del mundo, o de sí misma, pues se concibe como una experiencia liminar.

Palabras ClaVe: viaje, locura, noción del pliegue, Foucault, Patricia Laurent Kullick.

\section{Abstract:}

This article elaborates a reading of the novel by Patricia Laurent Kullick, El Camino de Santiago (2003), from the topic of the journey that is problematized in the story. The analysis is made from Michel Foucault's (1972) proposal around the depiction of The Ship of Fools, emblematic of a certain madness that travels and arouses imaginaries around its manifestations. Later, this image of the ship of fools will be enriched with Deleuze's (2015) proposal, and his notion of the fold, which the author relates to the ship of fools analyzed in The History Of Madness. Based on the notion of fold, we will analyze the supposed schizophrenia of the protagonist of El Camino De Santiago, a "disease" that takes a metaphorical form allowing us to explore a sense of madness as an escape, but above all, as a trip to the inner self and the exterior of the world, or of herself, since madness is conceived as a liminal experience.

KEYWORDS: travel, madness, notion of the fold, Foucault, Patricia Laurent Kullick.

Históricamente, la locura ha significado un enigma fascinante en la cultura occidental. A partir del siglo XIX, adquiere un nuevo estatus de "enfermedad" gracias al poder psiquiátrico, que se adueña de su verdad y la confina al encierro. Desde entonces, la ciencia despoja a la locura de su fuerza y su posibilidad de decirse a sí misma.

Sin embargo, la cultura occidental siempre ha intuido elementos que superan el discurso de la ciencia y su supuesta verdad sobre la locura. Este presentimiento es muy visible en la literatura, desde el Quijote personaje cervantino del siglo XVII- que enuncia la locura dándole sentidos muy complejos y polifónicos, hasta la novela contemporánea, en donde se le sigue tratando desde el enigma, como algo que supera la ciencia y su voluntad de verdad. En la literatura, la locura encuentra un lugar donde puede manifestarse desde otras voces, aunque siempre se la ve enfrentada a la mirada y la voluntad de los que la quieren definir o dominar.

$\mathrm{Al}$ acercarnos a la primera novela de Patricia Laurent Kullick, El Camino de Santiago, el tema de la locura resulta también esencial y es abordado en el relato desde una perspectiva que resulta compleja y problemática. Esta novela fue publicada en la editorial Era en el 2003. Luego se tradujo al inglés para publicarse en el 2004 en 
la editorial inglesa Peter Owen (Villarreal, 2008). Para Eduardo Antonio Parra (2004), su línea de narración, junto con escritores tales como el mexicano David Toscana (1961), explora una temática personal. Los relatos de Laurent y su novela ${ }^{1}$ presentan "estupendas disecciones del alma femenina" y "revelan a una narradora con gran capacidad de introspección y un humorismo único en las letras nacionales" (p. 76).

La protagonista del relato es una mujer que cuenta su historia personal a través de una narración en la que convergen tres personajes que constituyen la voz narrativa: ella misma (voz anónima y centro del relato), Santiago y Mina. De tal forma, Santiago y Mina se perciben como personajes que viven solo en la mente de la protagonista. Por un lado, Santiago se presenta como una voz masculina que intenta dominar a la protagonista a través de una domesticación de su cuerpo, de su comportamiento y de sus prácticas cotidianas. Este personaje aparece en su vida luego de un intento fallido de suicidio en su adolescencia. Por otro lado, Mina es una voz femenina que le permite a la protagonista sentirse libre y confiar en sus instintos y deseos.

Tal como lo propone Valero (2016), la "dualidad Mina-Santiago reedita la polarización estereotipada entre lo femenino y lo masculino.” (p.90). Al mismo tiempo, hay que agregar que entre ellos hay una lucha. Santiago ha confinado a Mina a un espacio de la mente de la protagonista del que no puede escapar ni manifestarse en forma alguna. Y esta es una de las razones por las que la protagonista desprecia a Santiago.

En cuanto a la protagonista, el discurso de la crítica la ha caracterizado a partir de una aparente ausencia de identidad o más bien una "identidad múltiple y contradictoria" (García, 2010, p. 18). Ha percibido a este sujeto caótico desde la imagen del collage, no solo en la estrategia narrativa, sino también en la construcción del personaje: un rejuntado de cosas fragmentadas y caóticas que remiten a un sujeto en crisis frente al racionalismo (García, 2010). Se trata, en todo caso, de un personaje escindido y su historia está en las intersecciones entre "la esquizofrenia clínica y la metafórica" (Palaversich, 2004).

En ese sentido, para Tarazona, los rasgos construidos por la protagonista responden a situaciones de incertidumbre frente a las que improvisa creando identidades "prodigiosas, anómalas y fantásticas" (2014, p. 181). Su forma de ser "fluctúa", como lo señala Valero citando a Tarazona (2014), "entre lo insólito y lo sobrenatural":

[...] una identidad que conocemos en retrospectiva desde la edad adulta hacia la niñez, adolescencia y juventud (traspasada por un intento de suicidio a los catorce años) y en cuyo discurrir se suceden todos y cada uno de los estados apuntados por Tarazona: "el nacimiento, la caída, el desasosiego y la euforia, la definición de la identidad, presenciados por íncubos y súcubos, por fantasmas y seres con cualidades bestiales” (Valero, 2016, p. 89).

Esta presencia del desdoblamiento en la identidad de la protagonista es característica de la "narrativa de lo inusual” en la que se inscribe El camino de Santiago según Valero (2016) y García-Valero (2020), quienes indican que se trata de un concepto propuesto por Carmen Alemany en varios de sus trabajos:

La etiqueta de "narrativa de lo inusual" nos permite amparar una literatura que se mueve en baremos no usuales, infrecuentes;
pues no hay en sus discursos una intencionalidad explícitamente fantástica aunque sí la necesidad de acudir a otros
parámetros que fluctúan en la franja que oscila entre lo real y lo insólito [...] pero que termina por detenerse en lo primero.
Una forma de ficción en la que prima la incertidumbre aunque los hechos trascurran en el plano de lo real con transiciones
hacia lo onírico o lo delirante; y en ese trance el autor abandona al leyente en su perplejidad, pues esta ambigüedad tiende
a provocar la vacilación interpretativa del lector. Sus discursos se nutren de tropos que proceden fundamentalmente de lo
poético -analogías, metáforas, comparaciones, alegorías- que les sirven para explicar de otro modo lo real, una realidad que
finalmente vuelve con todo su peso (Alemany, 2016, p. 135).

En esa medida, para Tarazona (2014), el cuerpo de la protagonista se percibe como una "metáfora de lo fantástico":

Pero nótese que Tarazona habla de "metáfora de lo fantástico" y no de lo fantástico en sí. Es, pues, el cuerpo metáfora del particular mundo imaginario que hilvana la novela y espacio de una errancia de la identidad, que se formula desde el doble punto de vista anímico y físico (Valero, 2016, p. 93). 
Se puede decir que su historia es muy íntima y muestra su lucha por ser aceptada en la sociedad y al mismo tiempo su deseo de ser libre. En ese sentido, ella se percibe a sí misma siempre ajena y fuera de lugar en su condición de mujer ${ }^{2}$. Santiago parece aprovecharse de esto para someterla a las normas a través del control de su cuerpo. Por lo tanto, se puede pensar en él como en una metáfora de la razón, e incluso de la "normalidad".

La experiencia de la protagonista permite acercarnos a un tópico clásico de la literatura: el del viaje. Tal como se puede ver en las grandes obras de la literatura universal como El Quijote, La Odisea, La Divina Comedia, etc., el viaje representa un espacio de transformación en el que los protagonistas crecen y se vuelven complejos. En el caso de la novela de Laurent, el viaje se presenta no como su elemento constitutivo básico, sino más bien como un espacio en el que se posibilita la locura de la protagonista, es decir, el viaje va a permitirle construirse desde un lugar libre de la razón, representada por Santiago, y por ello, en este artículo, me interesa analizar la imagen del viaje como efigie de la locura, espacio de transformación y de posibilidades.

A partir de la propuesta de Michel Foucault en torno a la figura de la Nave de los locos, emblemática de cierta locura que viaja y que no deja de resultar un enigma, haré una lectura de la experiencia del viaje de la protagonista de El Camino de Santiago. La imagen de la nave remite también a la noción del pliegue de Deleuze (2015), la cual permite problematizar aún más el tema del viaje en la novela. Desde esta perspectiva, la supuesta esquizofrenia de este personaje toma una forma metafórica que permite explorar un sentido de la locura como el escape, la huida, pero ante todo, como un viaje al interior y el exterior del mundo, o de sí misma, pues se concibe como una experiencia liminar.

\section{Los locos en SU NaVe: El Viaje Desde Michel Foucault}

En Histoire de la folie à l'âge classique (1972), Michel Foucault realiza un análisis de la locura como una construcción histórica y cultural. Su propuesta es hacer un estudio arqueológico de la locura, que se percibe desde ahí, como algo susceptible de transformación. Por ello, a través de momentos históricos, indaga en torno a las experiencias y conciencias de la locura. Su estudio inicia en la Edad Media, luego sigue en el Renacimiento, el periodo llamado neoclasicismo y culmina en el siglo XIX.

A finales de la Edad Media, aparece lo que Foucault llama "la experiencia trágica de la locura", que se extiende hasta mediados del Renacimiento.

Esta experiencia trágica adopta una figura cósmica: la gran razón del mundo (el orden de las cosas, su naturaleza) se ve debilitada por las "amenazas" destructivas de una locura soberana que volvería a arrojar el universo en un inmenso furor. Y toda la historia posterior de las conciencias de la locura sólo se vuelve posible contra el fondo de la desaparición, el necesario olvido, el ocultamiento de esta conciencia trágica primitiva. (Gros, 2000, p. 39).

En este contexto, la locura adquiere una importancia sin precedentes: lo que constituye una amenaza ya no es la muerte, sino el delirio. Se trata de una locura que tiene "furor", es soberana pues tiene poder para crear el caos en el universo. Constituye un peligro pues tiene la capacidad de "quebrar los límites establecidos de un orden razonable" (Gros, 2000, p. 42). En esta experiencia trágica hay figuras simbólicas muy relevantes en este análisis. La Nave de los locos es una de ellas. Esta figura simbólica aparece en el Renacimiento y ocupa un lugar privilegiado (Foucault, 1972, p. 21). El "Narrenschiff” o "Stultifera Navis" es una composición literaria del alemán Sebastian Brant, de 1494, en donde se hace una crítica moral de los vicios de la época:

Le Narrenschiff, évidemment, est une composition littéraire, empruntée sans doute au vieux cycle des Argonautes, qui a repris récemment vie et jeunesse parmi les grands thèmes mythiques [...] La mode est à la composition de ces Nefs dont l'équipage de héros imaginaires, de modèles éthiques, ou de types sociaux, s'embarque pour un grand voyage symbolique qui leur apporte sinon la fortune, du moins, la figure de leur destin ou de leur vérité (Foucault, 1972, p. 22).

Lo interesante es que estas "naves de locos" realmente existieron en la primera mitad del siglo $\mathrm{XV}^{3}$. Los barcos cargados de locos navegaban de una ciudad a otra, pues sus tripulantes eran expulsados de sus pueblos, 
de sus ciudades, y adquirían en consecuencia, una "existencia errante" (Foucault, 1972, p. 22, traducción propia). Para Foucault, esas naves adquieren significados "altamente simbólicos" (Foucault, 1972, p. 24, traducción propia). Por un lado, se cree que la partida del loco responde a un viaje en búsqueda de la razón. Por otro lado, el hecho de confiar el loco a los marineros es una forma de convertirlo en prisionero.

Hay que recordar que este encierro es de carácter simbólico pues es hasta el siglo XVII que se establece la práctica de la reclusión de la locura asociada con una serie de faltas sociales: la pobreza, el alcoholismo, la criminalidad, etc. Luego, en el siglo XIX, se deja de pensar la locura como un error, y se le empieza a entender en relación con el comportamiento llamado "normal". Ahí es cuando la locura se convierte en un trastorno (Foucault, 1977, p. 143). Surge así lo que Foucault llama la "conciencia analítica" de la locura que aparece en ese siglo y que supone una mirada que se fundamenta en el saber de la ciencia (Foucault, 1972, p. 220). Esta conciencia cierra definitivamente el diálogo con la locura, aplaca los horrores y los fantasmas del pasado, pues lo que provoca temor va a ser dominado a través de la "técnica de la supresión" (Foucault, 1972, p. 221). Se trata pues del conocimiento de la locura que pasa por la ciencia y por la objetividad del científico. Esta conciencia es la que todavía tenemos hoy en día (Díaz, 2005, p. 63). Desde el análisis que hace Foucault en Histoire de la folie, con el "gran encierro" ${ }^{4}$, se aplaca la experiencia trágica de la locura, esto es, se silencia su furor, su fuerza, para que deje de ser amenaza a la razón, en las conciencias de la locura ${ }^{5}$.

En la nave, es la exclusión la que encierra al loco, la prisión está en el lugar de pasaje, pues el navegar es el "Pasaje absoluto", "desarrolla, a lo largo de una geografía semi-real y semi-imaginaria, la situación liminar del loco en el horizonte de las preocupaciones del hombre medieval” (Foucault, 1972, p. 26, traducción propia).

Et plusieurs fois au cours des temps, le même thème réapparaît: chez les mystiques du XVe siècle, il est devenu le motif de l'âme nacelle, abandonnée sur la mer infinie des désirs, dans le champ stérile des soucis et de l'ignorance, parmi les faux reflets du savoir, au beau milieu de la déraison du monde -nacelle en proie à la grande folie de la mer, si elle ne sait jeter l'ancre solide, la foi, ou tendre ses voiles spirituelles pour que le souffle de Dieu la conduise au port. (Foucault, 1972, p. 27).

La exclusión de los locos en los barcos tenía un sentido ritual: "su significación es la de una ceremonia, más que la de una mecánica social ciega" (Gros, 2000, p. 40). De tal forma, aquella práctica tenía una utilidad social importante: deshacerse de ese personaje incómodo y afirmar la seguridad de los ciudadanos encerrándolo en su partida, asegurándose de que no fuera a estar rondando por los muros de la ciudad.

Sin embargo, el significado simbólico resulta más interesante. Para Foucault el agua se convierte en un agente purificador: es la que se lleva a los locos, pero al mismo tiempo, los purifica. Además, en el agua, el loco está abandonado a la suerte, a lo que el destino haga de él: "[...] là chacun est confié à son propre destin, tout embarquement est, en puissance, le dernier. C'est vers l'autre monde que part le fou sur sa folle nacelle; c'est de l'autre monde qu'il vient quand il débarque" (Foucault, 1972, p. 26).

En la despedida, parte para otro mundo y, en su llegada, viene de otro mundo. En este sentido, el viaje del loco acentúa su situación liminar: el loco es el límite mismo. Prisionero del lugar de pasaje está abierto a distintas "posibilidades de mundos". Mundos para los cuales, su posible llegada es una revelación, pero sobre todo, una amenaza de invasión, pues la locura, en esta experiencia trágica, reitero, es amenaza y peligro:

Il est prisonnier au milieu de la plus libre, de la plus ouvertes des routes: solidement enchaîné à l'infini carrefour. Il est le Passager par excellence, c'est à dire, le prisonnier du passage. [...] Il n'a sa vérité et sa patrie que dans cette étendue inféconde entre deux terres qui ne peuvent lui appartenir [...] Une chose au moins est certaine: l'eau et la folie sont liées pour longtemps dans le rêve de l'homme européen. (Foucault, 1972, p. 26).

\section{BUCEANDO EN LAS CAVERNAS INTERIORES: EL VIAJE DE LA PROTAGONISTA}

En El Camino de Santiago, la protagonista y Santiago son ambos viajantes. El título enfoca bien el "camino" de Santiago, pero al mismo tiempo, evoca el "camino" de la protagonista: tal como lo propone Valero, el título se refiere al "camino interior de ella" así como al "camino de su vida" (2016, p. 91). El viaje de la 
protagonista tiene un carácter simbólico, para entenderlo hay que aclarar que en el relato su historia se va construyendo a través de fotografías a menudo presentadas por Santiago. Ellas muestran casi siempre escenas dolorosas de su infancia, adolescencia y de su vida adulta. En la narración de un recuerdo-fotografía de su niñez, la protagonista y sus hermanos reciben un castigo particular, cuando su comportamiento desafiaba al padre, este les obliga a pasar la noche en el patio de la casa. Para soportar el horror que le causa quedarse sola en la oscuridad del patio, el personaje femenino aprende un truco que parece un mecanismo de defensa: se desmaya como para evadir o ausentarse. Sin embargo, lo que parece un simple desvanecimiento es una especie de desconexión con la realidad que adquiere el sentido de un viaje y parece incluso ocurrir en el agua:

De pronto, sin saber exactamente cómo, borro la memoria. Estoy con los ojos volcados hacia atrás, buceando en las cavernas interiores. Luego la nada. Ninguna memoria u objeto. Nada. He retrocedido hasta el azul del abismo y caigo. Floto sin cuerpo, sin ojos, sin lenguaje. (Laurent, 2003, p. 32).

Es decir, el maltrato del padre provoca el "viaje" de la narradora y en él, ella "bucea”, aparentemente, en el interior de su cuerpo, de su ser. Están presentes aquí las ideas del viaje y del agua -elementos esenciales del motivo de la Nave de los locos-. Se trata de un viaje en el que ocurre un abandono de todos los referentes. Es la caída en la "nada". Luego de caer, flota, y el flotar remite nuevamente a la existencia errante del loco, a la incertidumbre de la navegación. Además, en ese momento, ya no hay voluntad, simplemente se deja llevar, es transportada, no ve ("sin ojos"), no habla ("sin lenguaje") y no siente ("sin cuerpo"): "Es un vuelo donde el silencio arremete a los tímpanos. Me integro perfectamente al vacío. Santiago no está invitado con su cámara fotográfica, de manera que resulta imposible narrarlo" (Laurent, 2003, p. 32).

El viaje -expresado como navegación, buceo o vuelo- se caracteriza por ese vacío en donde reina el silencio, pero parece un silencio ensordecedor. Y aquí, en este espacio incierto del viaje, "Santiago no está invitado". Si se piensa que Santiago simboliza la razón de la narradora, es coherente pensar que, en la Nave de los locos, no hay lugar para ella pues es "un vuelo donde el silencio arremete a los tímpanos" (Laurent, 2003, p. 32). El silencio del mar, del viaje, tiene más potencia ensordecedora que el ruido cotidiano, fuera del viaje. En la ausencia de razón (de Santiago), tampoco está su cámara fotográfica y, por lo tanto, la protagonista está libre de los recuerdos dolorosos que evoca la razón/Santiago cuando quiere que la protagonista entre en "razón".

La protagonista emprende este viaje de nuevo en momentos particulares. Uno de ellos ocurre cuando una de sus parejas resulta ser un terrible agresor. Luego de secuestrarla y violarla, ella vuelve a "irse" pues es la única forma que encuentra para escapar del horror que vive con ese hombre, quien no puede acompañarla "a donde los ojos se vuelcan al abismo" (Laurent, 2003, p. 32): "Vicente está furioso. No puede acompañarme [...]. Estoy recostada sobre un sofá. Levanto los hombros con la mirada puesta en el truco infantil. Llevamos días así. Él me hace el amor y yo remonto el vuelo lejos de todo sentimiento” (Laurent, 2003, p. 32).

El viaje sucede nuevamente hacia el final del relato, cuando a la protagonista la hospitalizan, y entonces, ante el mundo amenazante, vuelve a escapar:

Sin levantar la menor sospecha, me adentro en la oscuridad del cerebro. Inmóvil espero acostumbrarme a la engañosa claridad rojiza. Santiago está de espaldas, sentado frente al motor ocular desde donde dirige la vista al doctor como si jugara con unos binoculares gigantes. (Laurent, 2003, p. 96).

A pesar de que el viaje parece ocurrir en el interior de su cuerpo, se puede entender más bien desde la noción de pliegue de Deleuze, sobre la que me detendré brevemente. En La subjetivación. Curso sobre Foucault Tomo III, dictado el 22 de abril de 1986, el filósofo intenta definir y problematizar acerca del tercer eje en el pensamiento de Foucault. Luego del eje del saber y el del poder, hay un tercer eje que se relaciona con "el afuera". El afuera se entiende como un espacio donde las fuerzas se relacionan. Cuando se "alcanza" la línea del afuera, se descubre un "afuera absoluto". Blanchot se refiere a esta línea como una "imposibilidad", sin embargo, Deleuze dice que no hay más posibilidad que llegar ahí, "hasta esa imposibilidad misma” (2015, p. 12). 
Deleuze da una explicación relacionada con el tema de la resistencia en Foucault, quien en La voluntad de saber propone que "los puntos de resistencia son la simple contracara de las relaciones de fuerza" (2015, p. 12). Ante esto, Deleuze protesta: “¿Cómo podía decir que eran simples contracaras, cuando la contracara de la fuerza afectante es la fuerza afectada, no la resistencia?” (2015, p. 12). Por lo tanto, Deleuze concluye que la resistencia al poder viene más bien del afuera:

Lo que vimos la última vez [...] es que al final de su período de reflexión sobre el poder, Foucault se encuentra en un impasse, que no es su impasse, sino el del poder mismo. A saber: ¿`cómo franquear la línea del poder? O bien, es lo mismo: ¿cómo alcanzar un afuera que sea verdaderamente un afuera? [...] Un más allá del poder que sería la relación con el afuera, pues el poder solo nos daba una relación indirecta o mediatizada. (Deleuze, 2015, p. 14).

Como se ve en la cita, se apunta a ir más allá del poder, a una dimensión que esté afuera del poder, y esta dimensión es la línea del afuera, que está más lejos que "toda forma de exterioridad" (2015, p. 14). Ahora bien, en el intento de ofrecer una idea de esa línea del afuera, Deleuze recurre a Blanchot, quien a partir de imágenes metafóricas, da una imagen de la línea del afuera a través de la construcción verbal "se muere":

La idea más completa que nos daba es "se muere". La línea del afuera es "se muere". Es importante la fórmula "se muere". Blanchot no dice que es la línea de la muerte, sino que lo que forma la línea del afuera es "se muere". Y los textos más conmovedores y los más avanzados de Blanchot al respecto están en El espacio literario. El "se muere" es la relación con el afuera [...] Blanchot se esfuerza en hacernos comprender que la muerte es fundamentalmente doble: hay una muerte que se enuncia bajo la forma "yo muero", y una muerte que se enuncia bajo la forma "se muere". [...] Yo diría que la muerte del "yo muero" es la muerte como instante indivisible, es la muerte que puede llegarme, que me llegará. Es en cierto modo la muerte personal. La muerte del "se muere" es la muerte coextensiva a la vida, una muerte que siempre ya ha comenzado y no termina. Es coextensiva a la vida. [...]. Es la no-relación con la muerte. [...] La muerte interminable [...] (Deleuze, 2015, p. 15).

De tal forma, la línea del afuera se relaciona con una muerte que es "coextensiva a la vida", que no tiene final, frente a la muerte del "yo muero" que es una muerte terminada. La línea del afuera es esa muerte perpetua, de tal forma, aunque haya algo más allá del poder, un "franqueamiento del poder" que es la línea del afuera, lo que se encuentra es una muerte coextensiva a la vida. Se plantea aquí la idea de que para poder escapar del poder, hay que pasar por la muerte. Como si la muerte fuera la última salida al poder.

Evidentemente estaríamos muy, muy contentos, si algo viniese a sacarnos de aquí. ¿Pero qué puede lograr esta línea del afuera, sino ser mortal, es decir, aportarnos la muerte, como si solo a través de ella se pudiera esquivar el poder? Todo se arreglaría, evidentemente, si tuviéramos motivos para pensar que la muerte coextensiva a la vida no agota la vida. Más aún, para que todo sea relanzado sería preciso [...] que la línea sea capaz de ciertos movimientos que la arranquen de la muerte. (Deleuze, 2015, p. 21).

En el razonamiento de Deleuze se hace entonces necesario buscar alguna salida a esa muerte, y la solución tiene que ver con esos "movimientos" de la línea del afuera que la alejen de la muerte interminable. Como si para poder escapar de la muerte, del "carácter mortífero" de la línea de afuera, se hiciera necesario saltar el "poco profundo arroyo de la muerte" (Deleuze, 2015, p. 21). Y para lograrlo es preciso un movimiento de la línea del afuera. De tal forma, el afuera debe producir un movimiento que formará un adentro, y este movimiento es el pliegue:

Digo que es preciso que la línea del afuera sea recorrida por un movimiento que es el pliegue. Es preciso que se pliegue. Es la invaginación. Es preciso que se pliegue, siendo el pliegue constitutivo de un adentro más íntimo que todo medio de interioridad, más cercano que todo medio de interioridad. [...] Es preciso que haya un pliegue de la línea, y ese pliegue es lo que arranca de la muerte a la línea. (Deleuze, 2015, p. 23).

En vista de que se señala un "adentro", Deleuze insiste en que ese adentro es un adentro del fuera, y de ninguna manera un adentro que se refiere a una interioridad del sujeto:

No hay ninguna restauración de una interioridad en Foucault en el sentido de $m i$ interioridad. Hay simplemente un movimiento del afuera por el cual se constituye un adentro del afuera. Solo el afuera tiene un adentro. Y es esto lo que Blanchot había comprendido muy bien a propósito de Historia de la locura, cuando decía que lo que está encerrado es el 
afuera. A saber: solo el afuera tiene un adentro. [...] En otros términos, el adentro es el adentro del afuera. No es lo contrario del afuera, es el adentro del afuera. Es el pliegue del afuera. (Deleuze, 2015, p. 24).

Algo que resulta particularmente interesante en esta lectura, como se ve en la cita, es que Deleuze recurre a Foucault, en La Historia de la locura, para dar una imagen del pliegue, cuando opone la tierra y el mar, para hablar del saber que es de la tierra firme, y de la línea del afuera que es acuática, oceánica. Es decir, la línea del afuera es el mar, el espacio que está más allá del poder, el del "se muere", el de la muerte eterna. Y el adentro de la línea del afuera es el barco: la nave de los locos. Ese es el pliegue del mar. "Cada vez que hay un barco, el océano ha hecho un pliegue" (Deleuze, 2015, p. 24).

Y Foucault tiene un texto espléndido, página 22 de la Historia de la locura. A propósito del loco arrojado a su nave, dice esto que leo lentamente: Es puesto en el interior del exterior, e inversamente. [...] El loco es puesto en el interior del exterior cuando es arrojado a su nave. Prisionero de la más libre, de la más abierta de las rutas, sólidamente encadenado a la encrucijada infinita. Es el Pasajero por excelencia, es decir, el prisionero del pasaje. En otros términos, es puesto en el interior del exterior [...] Los términos son equivalentes, se podría decir también que es puesto en el adentro del afuera. El adentro es el adentro del afuera, y no hay otro adentro que el del afuera. (Deleuze, 2015, pp. 24-25, cursiva del original).

Como se ve en la cita, el loco está precisamente en el pliegue, en el adentro del afuera, a salvo del "se muere" y afuera del poder, en el espacio de la resistencia, del pliegue de la línea del afuera. Esto es lo que sucede con la protagonista de El Camino de Santiago, el viaje que vive no ocurre ni por dentro ni por fuera, sino por una superficie que se extiende y que, cual botella de Klein, no tiene interior ni exterior, tal como lo explica la Dra. Hounie:

Para acercarnos a la idea de esta continuidad entre lo exterior e interior, Lacan toma prestada de la topología, la figura de la llamada "botella" de Klein. Ella permite figurar la ruptura con todas las dicotomías dadas por los falsos dualismos mundo interno-mundo externo, psicología individual - psicología social, adentro-afuera pues muestra una superficie cerrada cuyo interior comunica integralmente con su exterior, por lo que no tiene un "adentro" y un "afuera". Al igual que la "Banda de Moebius”, tiene una sola cara, pero a diferencia, no tiene bordes (Hounie, 2013, p. 246).

La protagonista entra en la embarcación, así hace el pliegue, el adentro del afuera, mas no para constituir el "adentro" del sujeto. Está en una dimensión a salvo del poder, a salvo del "se muere", de la "muerte interminable" (Deleuze, 2015, p. 15).

Al mismo tiempo, su experiencia se concibe infinita, caótica e impredecible como el mar. Tiene por lo tanto un carácter oceánico al igual que la sinrazón que ha sido siempre acuática en la imaginación de Occidente (Foucault, 2001, p. 196), por ello comparte la "inquietud incesante del mar" y sus "caminos desconocidos" llenos de "extraños saberes" (Foucault, 1972, p. 27, traducción propia). En cambio, la razón está en tierra firme:

Dans l'imagination occidentale, la raison a longtemps appartenu à la terre ferme. Île ou continent, elle repousse l'eau avec un entêtement massif: elle ne lui concède que son sable. La déraison, elle, a été aquatique depuis le fond des temps et jusqu’à une date assez rapprochée. Et plus précisément océanique: espace infini, incertain. (Foucault, 2001, p. 296).

La razón que constituiría el mundo de Santiago es el mundo de afuera, lo opuesto del viaje, la tierra firme, lo estático, lo conocido, la certidumbre, lo "normal": el mundo que quiere dominar Santiago. En el mar de la sinrazón, donde ella escapa, a menudo encuentra a Santiago, pero el encuentro nunca es de frente, sino que lo presiente de lejos. Por ejemplo, cuando la protagonista está hospitalizada y escapa de nuevo de la "realidad", lo ve sentado "frente al motor ocular [...] como si jugara con unos binoculares gigantes". Es decir, desde su "nave" observa a Santiago (¡o a su razón?), y percibe cómo él maneja su cuerpo, cómo la maneja a ella. Y en esa percepción, es "como si" Santiago "jugara" como un niño, sin pensar en sus actos o en las consecuencias, reafirmando su carácter cínico y hasta su crueldad.

Esta dicotomía de Foucault, que asocia a la sinrazón con lo acuático y a la razón con la tierra firme, es coherente también con el viaje de la protagonista cuando ella lo describe como bucear, pero también como "volar" o "flotar", todas acciones que la alejan precisamente de la tierra. Otro detalle está en las borracheras 
de la protagonista. Ella, a menudo bebe alcohol para silenciar a Santiago y justamente, según Foucault, el tema de la "ivresse" (ebriedad) se lo debemos a esta "liquidez esencial de la locura" (Foucault, 2001, p. 296, traducción propia):

C'est peut être à cette liquidité essentielle de la folie dans nos vieux paysages imaginaires qu'on doit un certain nombre de thèmes importants: l'ivresse, modèle bref et provisoire de la folie; les vapeurs, folies légères, diffuses, brumeuses, en voie de condensation dans un corps trop chaud et une âme brûlante [...] (Foucault, 2001, p. 296).

Cuando la protagonista toma licor, entra en un estado líquido que silencia a Santiago, o a la razón. Como si incorporara el mismo líquido como circunstancia vital, se queda sin "puertos", sin lugares de llegada o de partida, totalmente "a la deriva":

Cuando me emborracho renace el amor infantil parecido al que sentí por el Tortas. Sin miedo ni método, sin la penosa necesidad de prolongarlo hasta el límite del abismo donde la carne ya no puede viajar. Así, con el cuerpo desparramado, flácido, Santiago no puede remar por el tráfico alterado de las señales cerebrales. Con la topografía inflamada, la telegrafía confusa, amé muchas veces. Amados que perdí al amanecer. Santiago salía renovado de sus cavernas. Me envenenaba con la cantaleta de la promiscuidad, fluidos indeseables y riesgo de contagio (Laurent, 2003, p. 16).

Se podría pensar que en su viaje, ella está en una especie de limbo o "terre inféconde" como le llama Foucault (1972, p. 26). Para los místicos del siglo XV, en efecto, el motivo de la Nave de los locos la muestra "abandonada sobre el mar infinito de los deseos, en el campo estéril de las preocupaciones, y de la ignorancia [...] en el centro de la sinrazón del mundo" (Foucault, 1972, p. 27, traducción propia). Entre dos tierras que no le pertenecen: su cuerpo y su vida. Su situación es absolutamente liminar. Está dentro de su cuerpo, pero no lo domina. Ve su vida, pero nada puede hacer por ella. Se mueve en los pliegues que intentan unir las dos dimensiones: el alma y el cuerpo, el adentro y el afuera.

Hacia el final de su recorrido, la protagonista escucha cómo Santiago va perdiendo el poder frente al médico que lo quiere sedar. Frente al galeno, hombre que ocupa un lugar de poder y de saber, Santiago se doblega por fin ${ }^{6}$ :

Todos han callado para dejarme oír la cólera de Santiago que grita, solloza, ruega. Dirige bien el manoteo de mi cuerpo contra el doctor que termina de vencerlo para inyectar una sustancia que cerrará los binoculares y paralizará el cuerpecillo de Santiago como una estatua sobre su montículo de miedo. (Laurent, 2003, p. 97).

Cuando finalmente lo derrota el médico, ella aprovecha que Santiago está dormido y encuentra su cubil: "Catacumba de carnes finamente talladas. Obra maestra y límpida de un inquilino falaz, obsesivo, extranjero. Hay en su mesa de trabajo el diseño horrendo del próximo delirio. Graficado en números y alucinantes geometrías tiene el mapa de mi cerebro" (Laurent, 2003, p. 97). El cubil de Santiago, lugar donde duerme la "fiera", es una "catacumba", es decir, un cementerio en donde "devora" a su víctima (la protagonista), y con su carne hace una estructura "finamente tallada". Por lo tanto, la descripción de Santiago en su cubil es la de un ser monstruoso, casi apocalíptico, cruel y, además, "falaz, obsesivo, extranjero". Esta es la imagen de la razón que problematiza el relato. Si Santiago es la racionalidad, esta se concibe en su monstruosidad como destructiva y cruel.

Luego, la narradora encuentra unas celdas que contienen fotos en blanco y negro. Una de ellas muestra a su madre adolescente a punto de ser violada, otra a su padre de niño, tocando el violín durante el entierro de su madre; y otra a su hermano Luis, "derrotado por la impotencia, mirando la desnudez de su esposa dormida" (Laurent, 2003, p. 98). Estas fotos parecen contener secretos de la infancia de sus padres y de su hermano y parecen funcionar como explicación de sus actos, de sus frustraciones, y hasta de su crueldad.

La narradora sigue su viaje. En una de las celdas hay un túnel y en su interior, las memorias:

Se desata una histeria de colores que luego se disipan para dejarme ver un túnel largo. Penetro. Adentro están las memorias. Les hablo; quiero tocar a mis hermanos, tocarme a mí misma que estoy con ellos, pero todos son como hologramas (Laurent, 2003, p. 98). 
Esta es la despedida. Ella ha entrado en el túnel de la muerte quizá, lo cierto es que no volverá a salir. Abandonada en el viaje -en la locura- pues sabe que Santiago no volverá tampoco. La locura es también como la muerte, el final de la razón, de Santiago y el final de la novela, de su historia, del lenguaje. Sin embargo, hay un encuentro importante al final del viaje (¿o al principio?). Presiente a Mina y le toma la mano:

Recorro un largo camino. El rojo se vuelve púrpura. Suspiro aliviada al presentir a Mina: reconozco el aliento desfatigado y pleno. No hay rencores por el intento que perdimos. Tomo la mano de su cuerpo azul y me vuelvo unos segundos para verme en la cama del hospital [...]. Sé que jamás saldrá de Santiago una palabra inteligible. Lucio me despide con su mejilla recargada en mi pecho tranquilo. (Laurent, 2003, p. 98).

Para la protagonista, Mina es la ternura, el afecto, el amor, lo tibio, el regazo. Representa su felicidad, placer y deseo. Un deseo inalcanzable y siempre añorado, retenido o capturado por Santiago; apartado de ella, contra su voluntad. De tal forma, este encuentro con Mina significa que al final no todo está perdido. Pudo liberarse de la razón, de Santiago, y aunque así se termina de perder en el viaje, en la Nave de los locos, encuentra algo de sí misma. Recupera su deseo y con él, una parte perdida de su ser.

Esto explica la visión de los secretos familiares, la cual le ayuda a amarrar cosas que revelan el dolor de la familia, causante de tanto tormento. Y el encuentro con las memorias que parecen darle un sentido de pertenencia. Como si terminara de acomodar los cabos sueltos de su existencia y de darle sentido a lo que antes era solo sufrimiento. Irónicamente, la viajante logra anclarse en el viaje y hacer el amarre que le devuelve el sentido de la vida, a pesar de encontrarse en la muerte, aunque esta sea simbólica.

Al final de la novela, ella queda en el espacio liminar del viaje, como lo plantea Foucault, el agua parece funcionar como un agente purificador que, a modo de viaje iniciático, le permite ver de lejos el final de la razón que la ataba y torturaba (la derrota de Santiago); y encontrar un sentido de pertenencia. Así logra tal vez recuperar algo de sí misma en el encuentro con Mina. Siempre expulsada por otros durante su vida, al final ella misma es la que prefiere la expulsión, que es el viaje. En ese sentido, parece escoger la locura, el espacio liminar, la ausencia de razón, frente a la "cordura" del mundo exterior, que fue siempre en su vida sinónimo de crueldad y dolor. Y en ese abandono a la locura, encuentra "su verdad y su patria" en esta "extensión infértil, entre dos tierras que no le pueden pertenecer" (Foucault, 1972, p. 26, traducción propia).

\section{REFLEXIONES FINALES}

El Camino de Santiago trata sobre experiencias de la locura situadas en un contexto contemporáneo, en esto se acerca a las producciones literarias de otras escritoras contemporáneas, tales como Laura Restrepo y Cristina Rivera Garza, entre otras. En este texto, la locura se sigue manifestando como polifónica, compleja e incluso inasible, pues su verdad, siempre fragmentada, va armándose desde distintas conciencias, tal como lo entiende Michel Foucault (1972).

Como se vio en el análisis, la locura se manifiesta desde la figura trágica del viaje, de la Nave de los locos. El viaje de la protagonista tiene un carácter oceánico, y ese principio acuático es precisamente el de la locura, de acuerdo con Foucault (2001). En esa lógica, la protagonista transita en una locura acuática que la aleja de la tierra firme (símbolo del mundo de la razón). Ella hace su viaje "desconectándose" de la "realidad", como en un desmayo, que es simbólicamente el inicio de un viaje en la locura que le permite descubrir, entrar en el caos, y al mismo tiempo encontrar protección frente a la fuerza destructiva de la racionalidad de Santiago.

En el viaje, la protagonista encuentra el pliegue, tal como lo propone Deleuze (2015): el pliegue de la nave, que hace el adentro de la línea del afuera, el lugar a salvo del "se muere" en el que la protagonista logra resistir al poder y encontrarse a sí misma, y a Mina. Por ello, el viaje es transformador e iniciático: permite crear nuevos mundos, nuevas subjetividades. 
Agua, locura y muerte se vinculan en la novela. La protagonista debe cruzar el agua -que se dibuja como la muerte en sus pesadillas- para llegar a Mina. Al final del relato, en su nave, se entrega a lo acuático, desafiando la muerte, más aún, escogiéndola como una opción que le permite por fin, reunirse con Mina.

\section{BibLiografía}

Alemany, C. (2016). Narrar lo inusual: Bestiaria vida de Cecilia Eudave y El animal sobre la piedra de Daniela Tarazona. Romance Notes, 56(1), 131-141.

Deleuze, G. (2015). La subjetivación. Curso sobre Foucault. (Tomo III). Buenos aires: Cactus.

Díaz, E. (2005). La filosofia de Michel Foucault. Buenos Aires: Editorial Biblos.

Felman, S. (1978). La folie et la chose littéraire. Paris: Editions du Seuil.

Foucault, M. (1972). Histoire de la folie à l'âge classique. France: Editions Gallimard.

Foucault, M. (1977). La casa de la locura. En F. Basaglia y F. B. Ongaro (Eds.), Los crímenes de la paz. Investigación sobre los intelectuales y los técnicos como servidores de la opresión (pp. 135-150). México: Siglo XXI Editores.

Foucault, M. (2001). Dits et écrits I. 1954-1975. Paris: Editions Gallimard.

García, L. (2010). La representación de la identidad individual en la narrativa mexicana de los albores del siglo XXI. Agathos: An International Review of the Humanities and Social Sciences, 1, 127-137.

García-Valero, B. (2020). Los trazos en el cuerpo, el cuerpo a trazos. Imaginario, lirismo y alteridad interior en la narrativa de lo inusual escrita por mujeres. Brumal, 8(1), 17-34.

Gros, F. (2000). Foucault y la locura. Buenos Aires: Ediciones Nueva Visión.

Hounie, A. (2013). La construcción de saber en la clínica. (Tesis doctoral). Universidad Complutense de Madrid.

Laurent, P. (2003). El camino de Santiago. México: Biblioteca.

Martínez Díaz, M. (2018). La locura como posibilidad de sublevación en El camino de Santiago (Patricia Laurent). En N, Mékouar-Hertzberg y S, Urdician (Eds.), Histoires de Folles. Raison et déraison - Liaison et déliaisons (pp. 85-108). France: Editions Orbis Tertius.

Palaversich, D. (2004). El camino de Santiago y la esquizoescritura de Patricia Laurent Kullick. Ciberletras: Revista de critica literaria y de cultura, (11).

Parra, E. A. (2004). El lenguaje de la narrativa del norte de México. Revista de Crítica Literaria Latinoamericana, 30(59), 71-77.

Tarazona, D. (2014). Los cuerpos insólitos en tres novelas de escritoras mexicanas contemporáneas. En F. J. Ordiz Vazques (Ed.), Estrategias y figuraciones de lo insólito en la narrativa mexicana (siglos XIX-XXI) (pp. 176-196). Bern: Peter Lang.

Valero J. E. (2016). En la brevedad del cuerpo y de la escritura: El camino de Santiago, de Patricia Laurent Kullick. Revista de Literatura Mexicana Contemporánea, 23(68), 87-101.

Villarreal, J. (2008). La razón vacía: El camino de Santiago de Patricia Laurent Kullick. Revista Replicante, (15), 119-123.

\section{Notas}

1 Otras novelas de Patricia Laurent publicadas posteriormente a la publicación de Parra son El circo de la soledad (2011) y La Giganta (2015).

2 Un análisis de la novela a partir de las posibilidades de la protagonista de resistir y escapar de la violencia que le impone el "ser mujer" puede ser leído en Martínez Díaz (2018).

3 De acuerdo con Foucault, en Alemania era muy frecuente ver estas naves de locos, durante la primera mitad del siglo XV. Menciona que a menudo las ciudades de Europa fueron testigos de las embarcaciones de locos (1972, p. 23). 
María Martínez Díaz. Navegar en la locura: el límite como posibilidad y Sentido en El Camino de Sa...

4 El "gran encierro" es la época en la que internan a 6000 personas en el Hospital General de París, corresponde con la creación del Hospital General en París en 1657. Esto ocurre después de la publicación de las Meditaciones de Descartes, en 1641. En la I Meditación, el filósofo excluye a la locura de la posibilidad del pensamiento (Felman, 1978, p. 41).

5 En Histoire de la folie, Foucault explica básicamente que la locura aparece en la conciencia de Occidente pero no es unívoca, sino que coincide con muchos procesos que van transformándola. De tal forma, no es posible captar el sentido de la locura de un momento histórico determinado en una sola unidad: su presencia es desmembrada (Foucault, 1972, pp. 215-216). Las cuatro conciencias (crítica, práctica, enunciativa y analítica) son evidencia del debate y de la complejidad que se experimenta ante la experiencia de la locura.

6 Cuando Santiago es derrotado por el galeno, se puede pensar en la derrota de la locura por el poder psiquiátrico. En esa medida. Se confunden la razón y la sinrazón, pues Santiago parece ocupar el lugar de la locura y no el de la razón; locura y cordura intercambian sus lugares; se pierden los límites entre ambas y todo se confunde. Al estilo carnavalesco, el mundo parece al revés, aunque sea momentáneamente. Es decir, el que clama más bien ser la razón, es la locura; el que clama ser la cura, es la enfermedad. De esta forma, el texto problematiza también la supuesta superioridad de la razón frente a la locura. 